\title{
Quantitative Analysis of Policy Transfer among China's National Innovation Independent Demonstration Zones
}

\author{
Feng Feng ${ }^{1} \&$ Qing $\mathrm{Li}^{2}$ \\ ${ }^{1}$ School of Management, University of Science and Technology of China, Hefei, China. \\ ${ }^{2}$ School of Public Affairs, University of Science and Technology of China, Hefei, China \\ Correspondence: Qing Li, School of Public Affairs, University of Science and Technology of China, No.96 Jin \\ Zhai Road, Hefei 230026, China. E-mail: liq4379@mail.ustc.edu.cn
}

Received: March 30, 2017 Accepted: April 13, 2017 Online Published: April 27, 2017

doi:10.5539/par.v6n1p19 URL: http://dx.doi.org/10.5539/par.v6n1p19

\begin{abstract}
Policy transfer is a process in which different organizations learn from each other to achieve policy innovation. It is also considered as an important channel of policy issuance. In China, national independent innovation demonstration zones serve as carriers of not only technological development, but also technological policies issued by China. Along with development of these national independent innovation demonstration zones, policy exchange and cooperation has become increasingly frequent among them. This paper attempts to find out different paths for policy transfer through a textual analysis of policies among China's national independent innovation demonstration zones. First, quantitative connotation and characteristics of policy transfer are analyzed. Then, a policy transfer quantitative evaluation index system is built based on three dimensions of policy transfer, namely intensity, breadth and speed. Following that, the quantitative evaluation index system is used to analyze policy transfer among national independent innovation demonstration zones. The paper tries to explore favorable policy categories for transfer, and learn the policy development status in these national independent innovation demonstration zones as well as the policy transfer trend from different perspectives. To sum up, this research can provide not only data support for policy innovation of China's independent innovational demonstration zones and accelerate their in-depth cooperation in terms of policy transfer, but also a new methodological research paradigm for quantitative analysis of policy transfer among parallel organizations.
\end{abstract}

Keywords: national independent innovation demonstration zone, policy transfer, quantization, policy innovation

\section{Introduction}

China's National Innovation Demonstration Zone (NIIDZ) are organizations built on the existing new-and high-tech industrial development areas to improve China's capability of independent innovation (Huang et al, 2013; Li, 2016). As platforms of national technological development and enterprises' independent innovation activities (Heilmann et al, 2013), these NIIDZs not only have the privilege of being first-movers of national policies (Audretsch et al, 2015), but also are shouldered with the mission of innovating and exploring systems (Bai et al, 2014), policies and management models in the field of China's technological development (Dong et al, 2014). Under the current development system, independent innovation of Chinese enterprises cannot be separated from national support (Bichler \& Schmidkonz, 2014; Strbac \& Pollitt, 2014; Lin et al, 2016). The establishment of NIIDZs is an attempt of China to lead Chinese enterprises to transition from the OEM (original equipment manufacturer) era to the era of independent R\&D (Chen, 2016). By taking in advanced development experiences from the international community, issuing different policies and combining various measures, NIIDZs play an important role in supporting development of Chinese enterprises in terms of infrastructure construction, financial and taxation services (Gao et al, 2015). Additionally, by reducing barriers of industry-university-research cooperation, NIIDZs have lifted China's NIIDZ capability to a new level (Ishengoma \& Vaaland, 2016). The past eight years have witnessed remarkable achievements of NIIDZs in the field of technological innovation. These achievements have been recognized by both the central government and the local government. In 2016 alone, China approved establishment of six NIIDZs. Emerging as brand-new organizations, these NIIDZs, though having different development concepts and management systems, keep on learning from each other. During the process, policy with its high adaptability has become the focus of mutual learning (d'Aquino \& Bah, 2014). Statistics show that, since establishment of NIIDZs, the number of policies 
transferred has accounted for more than $50 \%$ of total policies issued in different NIIDZs (Gao et al, 2015). This suggests that policy transfer has become a major source of policy formulation of China's NIIDZs.

Policy transfer is "a process in which knowledge about policies, administrative arrangements, institutions and ideas in one political setting (past or present) is used in the development of policies, administrative arrangements, institutions and ideas in another political setting." (Dolowiz \& Marsh, 1996, 2000; Evans \& Davies, 1999; McCann, E \& Ward, 2013) As an important activity of political organizations during their development process, policy transfer started gaining researchers' attention in the mid-late $19^{\text {th }}$ century (Wolman $\&$ Page, 2002). Walker (1969) analyzed policy formulation in different American states, finding out that their policies issued are not completely independent from each other but that there is a mutual influence among them. The influence is considered as a response to competition and solution of problems among organizations of the same kind. Based on Walker's findings, Gray (1973) pointed out that policy transfer has been quite mature among American states, and that a small-scale policy transform network has taken shape. By analyzing existing literatures, Dolowiz and Marsh (1996) defined policy transfer as a process, based on which they clarified connotation and characteristics of policy transfer. Since then, scholars have studied policy transfer based on findings of the above scholars. For example, Karen Mossberger and Harold Wolman (2003) regarded policy transfer as a process of policy analysis, in which the policy-maker evaluates the existing policies and the organization's status so as to introduce policies purposely and conditionally. Through case study of racial policy transfer, they explored a series of changes during the policy transfer process. By analyzing the case in which policies of American economic development zones were transferred to the British counterparts, Ian R. Cook (2008) focused on explicating factors involved in the cross-country policy transfer, including policy extraction, integration, innovation and social economic background. He also explored why these policies succeeded in America, and how the British counterparts modified these policies to copy the success of their American counterparts. Based on the successful case, Ian summarized characteristics of successful policy transfer. Russel Prince (2010) adopted the case in which British industrial innovation policies were transferred to New Zealand, and investigated into causes behind formation of internationalized policy transfer. He also discussed how organizations should overcome various difficulties during the cross-border policy transfer to make the transferred policies fit for the local cultural background. Matthew Gorton et al. (2009) analyzed development of EU's agricultural policies in Central European and Eastern European countries, and studied failure of policy transfer, thinking that geographical adjacency does not have a close bearing on success of policy transfer. According to their research, the organizational chart and the cognition of policies transferred among experts within the organization are two deciding factors of the success of policy transfer. Claire A. Dunlop (2009) mainly studied influence of the decision-maker during the international policy transfer process. Using the research methodology of knowledge community framework, Claire concluded that volatility and complexity of policy transfer compel the decision-maker to control information within certain scope, examine minor information changes and interact with the policy environment to draw up policies which can achieve corresponding objectives. Christoph Knill (2005) thought that, though an increasing number of scholars have combined policy transfer studies with the EU's integration process, convincing empirical research and in-depth interpretation are still lacking. Thus, it is necessary to conduct a quantitative research of policy transfer through re-exploration of the connotation of policy transfer based on characteristics of different subjects. Zhang et al. (2016) took a close look at transfer of policies concerning commercialization of technological achievements in China, and preliminarily proposed the concept of policy transfer quantization. These Chinese scholars thought that transfer characteristics and trend of these policies can be analyzed from four dimensions. However, though different scholars have studied policy transfer from different perspectives, most of them focus on studying causes and influencing factors of policy transfer. Meanwhile, too much emphasis on the international policy transfer have resulted in ignorance of the essence of policy transfer. Particularly, quantitative research of policy transfer is still new. What transfer quantization is and how transfer quantization is realized have not yet been illustrated. Without adequate horizontal analysis into characteristics of policy transfer quantization from the layer of the same subjects, outcomes of quantized policy transfer are dominated by upper-level laws.

Therefore, it is imperative to deepen quantitative research of policy transfer among different subjects. In this paper, the author proceeds from empirical research of policy transfer among China's NIIDZs. Policy transfer data from 2006 to 2015 among China's NIIDZs are collected, studied and classified. Next, based on research findings of previous scholars, the connotation of policy transfer quantization and the methodological research system are comprehensively proposed, and the policy transfer quantitative research paradigm is built. Meanwhile, through quantitative analysis of policy transfer, characteristics and development trend of China's national innovation demonstration policies are explored at an attempt to provide brand-new paths for policy transfer. Quantitative analysis of policy transfer can, on the one hand, provide a brand-new understanding of quantitative research of policy transfer, and get rid of shackles of the current policy transfer research. On the other hand, 
quantitative research of the policy transfer status among China's NIIDZs can effectively avoid subjective judgment coming along with qualitative research, allow researchers to get a more objective understanding of the development process of policy transfer, and offer scientific policy suggestions for a brilliant future of China's NIIDZs.

\section{Research Data and Methodology}

\subsection{Data Sources}

Some NIIDZs are newly built in China. These NIIDZs seriously lack policy samples. Concerning the problem, this paper selects six NIIDZs established for a long time and with a complete range of policy samples as research objects. These six demonstration zones are located in Beijing, Wuhan, Shanghai, Shenzhen, Sunan, and Chang Zhutan, respectively. Having evolved from new-and high-tech zones, these NIIDZs are characterized by a consistency in their policies. In order to guarantee completeness of policy transfer data, this paper selects policies issued by the six NIIDZs from 2006 to 2015 as research samples. Meanwhile, policies with a low relevance and with local characteristics are eliminated so as to ensure the policies collected to be more targeted. Finally, 823 pieces of technological innovation policies are collected in total.

Policy transfer refers to flow of information and knowledge between organizations. Under general conditions, the policy-maker will not fully copy policies from their counterparts. Instead, the policies transferred are usually adjusted based on the development status of the organization and problems arising in the policy implementation process. Or the policy-maker might issue similar policies based on concepts conveyed by the existing policies. These similar policies might get a name completely different from their predecessors, but there are no substantive differences between them in terms of content. In essence, the similar policies are still a transfer and absorption of existing policies. Take policies supporting development of SMEs (small-and medium-sized enterprises) for example. In 2007, Shanghai issued Measures on Implementing Shanghai Municipal Small Technological Giant Project. There were two goals Shanghai wanted to achieve with the newly-issued policies. First was to set examples for technological enterprises by supporting a batch of influential technological enterprises. Second was to provide fund support for these enterprises to develop into competitive players with international influence. Later, in 2010, Sunan released Several Suggestions for Implementation of "Double-Hundred Project"; in 2011, Wuhan introduced Opinions on Promoting Rapid Development of "Leading Enterprises"; in 2013, Beijing launched Work Plan for "Wing Plan" of Zhongguancun. Though these three policies differed in name and degree of fund support for enterprises, their core content showed their shared goal, that is, to select a batch of local technological enterprises with brilliant development prospects, accelerate their development through fund support and tax reduction and exemption and gear them to the international standards. Therefore, unlike citations in articles, most policy-makers will not directly mark policies from their counterparts of the same level they have referred to. Researchers need to extract the core content of policies to confirm whether policy transfer has happened. This paper thinks that, along with swift flow of information and increasingly frequent exchange among organizations of the same kind, once a policy is issued by one organization, other organizations can quickly acquire relevant information, and will more or less refer to the content of the policy while formulating policies of the same kind. In this paper, the reference process is defined as policy transfer. In order to achieve quantization of policy transfer, this paper describes different paths for policy transfer, and obtains 70 policy transfer links in total. Considering the large number of policy transfer links, this paper takes policies "supporting development of local enterprises" as a case study, based on which the policy transfer process is described. 


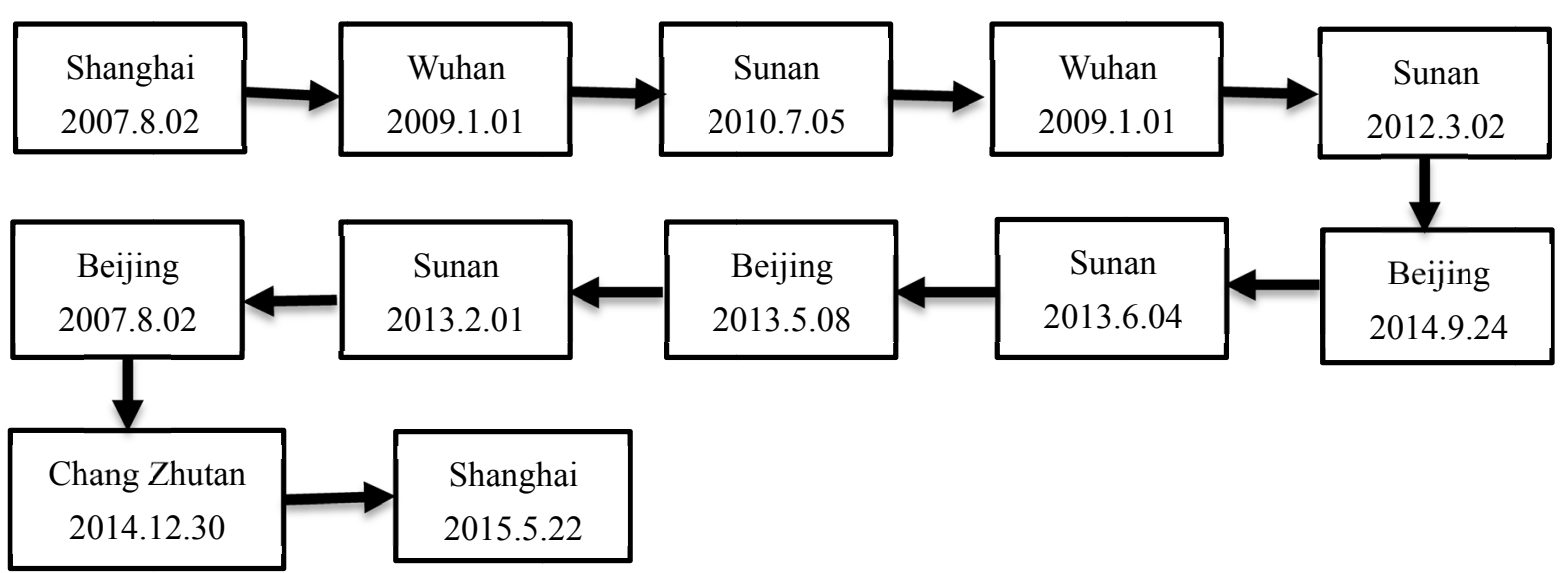

Figure 1. Transfer paths of policies "supporting development of local enterprises" among different NIIDZs

Notes. The content in boxes indicates the policy-maker and the date of policy issuance. The arrow stands for the direction of policy transfer.

As one notices, Shanghai is the source of policies "supporting development of local enterprises". Other NIIDZs play the role of policy initiators or acceptors on different nodes. It should be pointed out that Wuhan, Beijing and Sunan further enrich and improve their policies in accordance with their development period and policy implementation status. In this paper, the policy re-innovation is defined as self-transfer. Since every policy is independent, the statistical process of transfer times is also independent. For example, there are three policies involved in the transfer link of Wuhan, and two self-transfers occur during the transfer process. The three policies are all transferred from Shanghai.

\subsection{Research Methodology}

As on observes from the policy transfer path, quantization of policy transfer involves not only the number of policies, but also many other dimensions. Thus, all these dimensions should be taken into consideration so as to fully study policy transfer quantitatively. Zhang et al. (2016) examined quantitation of policy transfer from four dimensions, namely transfer intensity, divergence, speed and direction. However, they ended their research with the proposition of the four indexes without further clarifying how to achieve and measure quantization of policy transfer. Besides, in terms of the policy transfer direction, policy transfer between the upper level and the lower level might be easily distorted under the Chinese political system. Thus, this paper proposes measurement indexes for quantitative research of improved policy transfer between parallel organizations and methods to measure policy transfer quantitation.

In this paper, policy transfer quantization among China's NIIDZs involves three indexes or dimensions, namely transfer intensity, breadth, and speed. First, policy transfer intensity refers to the number of times, a policy is transferred since its issuance. In terms of policy transfer paths, transfer is not confined to transfer to other organizations. Sometimes, an organization issuing a policy might update the policy through some adjustments. Hence, policy transfer intensity includes not only transfer to other organizations, but also self-transfer. Generally speaking, the higher the number of times that a policy is transferred, the higher the quality of the policy is, and the higher the intensity of policy transfer is $P_{i}$. Second, policy transfer breadth refers to the number of organizations, a policy is transferred to. Usually, the higher the number of acceptors of a policy is $G_{i}$, the higher the geographical coverage of the policy is. Third, policy transfer speed reflects how fast a policy is transferred after its issuance from a time perspective. The time difference between the issuance date of a policy and the date when the policy is transferred for the first time. It is self-evident that, the shorter the time difference is, the faster the policy transfer is $T_{i}$. Based on the above explanation of the three indexes or dimensions, the quantization outcome of policy transfer is

$$
Q_{i}=\gamma \frac{P_{i}-P_{\min }}{P_{\max }-P_{\min }}+\delta \frac{G_{i}-G_{\min }}{G_{\max }-G_{\min }}+\varepsilon \frac{T_{i}-T_{\min }}{T_{\max }-T_{\min }}
$$

$\gamma, \delta, \varepsilon$ stand for the weight of the three indexes, respectively. Based on a survey among persons in charge among some NIIDZs, most respondents think that the three dimensions are of equal importance to policy transfer, so the weight of the three indexes should be the same. 


\section{Results and Discussions}

\subsection{Analysis of Policy Transfer Intensity}

Policy transfer intensity of China's NIIDZs refers to the number of times a policy is transferred on transfer paths. Transfer intensity can, to some extent, indicate popularity of a policy. The more the times a policy is transfer, the greater the importance a NIIDZ is attached to these policies. From 2006 to 2015, there were 1,025 times of policy transfer in total. This paper selects the top 10 policies with the highest transfer intensity to conduct an in-depth analysis of policy transfer in NIIDZs.

Table 1. Top 10 policies with the highest transfer intensity in China's NIIDZs

\begin{tabular}{|c|c|c|c|c|}
\hline Item & Policy name & $\begin{array}{c}\text { Issuer } \\
\text { (NIIDZ) }\end{array}$ & Policy type & Intensity \\
\hline 1 & $\begin{array}{l}\text { Temporary Management Measures for Hubei } \\
\text { Provincial Agricultural Technological } \\
\text { Achievement Commercialization Fund Project }\end{array}$ & Wuhan & $\begin{array}{c}\text { Technological } \\
\text { achievement } \\
\text { commercialization }\end{array}$ & 13 \\
\hline 2 & $\begin{array}{c}\text { Measures on Providing Fund Support for } \\
\text { Commercialization of New and High-tech } \\
\text { Achievements }\end{array}$ & Shanghai & $\begin{array}{l}\text { Technological } \\
\text { achievement } \\
\text { commercialization }\end{array}$ & 12 \\
\hline 3 & $\begin{array}{l}\text { Measures on Implementing Shanghai } \\
\text { Municipal Small Technological Giant Project. }\end{array}$ & Shanghai & Enterprise & 12 \\
\hline 4 & $\begin{array}{c}\text { Several Suggestions of CPC Beijing Municipal } \\
\text { Committee and Beijing Municipal People's } \\
\text { Government on Building Zhongguancun } \\
\text { Science Park }\end{array}$ & Beijing & Institution & 12 \\
\hline 5 & $\begin{array}{c}\text { Implementation Methods on Promoting } \\
\text { Construction of the Incubation System of } \\
\text { Technological Enterprises in Changsha } \\
\text { National High-Tech Industrial Development } \\
\text { Zone (Temporary) }\end{array}$ & $\begin{array}{l}\text { Chang } \\
\text { Zhutan }\end{array}$ & Enterprise & 11 \\
\hline 6 & $\begin{array}{l}\text { Methods on Trial Implementation on Shanghai } \\
\text { Municipal Major Infrastructure Purchase } \\
\text { Independent Innovation Achievements }\end{array}$ & Shanghai & $\begin{array}{c}\text { Technological } \\
\text { achievement } \\
\text { commercialization }\end{array}$ & 11 \\
\hline 7 & $\begin{array}{l}\text { Methods on Implementation of Hubei } \\
\text { Provincial Independent Innovation } \\
\text { "Double-100 Plan" }\end{array}$ & Wuhan & Enterprise & 11 \\
\hline 8 & $\begin{array}{c}\text { Suggestions of Suzhou Industrial Park for } \\
\text { Encouraging Entrepreneurship among Top } \\
\text { Technological Talents }\end{array}$ & Sunan & Talents & 11 \\
\hline 9 & $\begin{array}{c}\text { Notice on Accelerating Development of } \\
\text { High-Tech Talents (Shanghai) }\end{array}$ & Shanghai & Talents & 11 \\
\hline 10 & $\begin{array}{c}\text { Opinions of Hunan Provincial CPC Committee } \\
\text { and People's Government on Promoting } \\
\text { Development of Industrial Parks }\end{array}$ & $\begin{array}{l}\text { Chang } \\
\text { Zhutan }\end{array}$ & Institution & 11 \\
\hline
\end{tabular}

As one notices from Table 1, policies related to technological achievement commercialization, enterprise support and talent introduction show the highest transfer intensity. This suggests that NIIDZs pay more attention to development of these aspects. Among them, that technological achievement commercialization policies rank No. 1 in terms of transfer policy is no surprise. The major purpose of establishing these development zones is to promote independent innovation and realize upgrade of industrial transformation. Relevant research findings have shown that China is backward in terms of technological achievement commercialization level, which has seriously inhibited its technological industrialization. Many technologies remain in labs instead of turning into 
commodities. Through policy guidance of NIIDZs, external environment and internal institutions can be improved for technological achievement commercialization, thus effectively helping address the problem about deviation between technologies and market demands and accelerating transformation of economy from a labor-intensive one to one to one driven by technological innovation. Development of NIIDZs cannot be separated from growth and expansion of enterprises. This justifies the high transfer intensity of enterprise policies. Impacted by subjective and objective factors, China have long been in the middle and downstream of the global industrial chain. With few technological enterprises, China's technological level remains low. Under the condition, to develop a batch of medium-and large-scale technological enterprises, which can radiate their development vigor to surrounding and drive development of other enterprises, has become the top priority to NIIDZs. Different NIIDZs have invariably strengthened support for small-and medium-sized technological enterprises in the hope of fostering excellent local enterprises through the series of effective measures. Besides, as the cornerstone of technological development, talents have also been a focus of different NIIDZs. This is directly reflected by the high transfer intensity of talent policies in Table 1. Issuance of attractive talent policies can help NIIDZs attract top talents from different places both at home and abroad to join them and strive for sustainable development.

Usually, NIIDZs with a high policy transfer intensity are usually policy leaders. Policies issued by them are effective for being in line with development needs of NIIDZs. This is the main reason for high transfer intensity of policies from these NIIDZs to their counterparts. It can be seen from Table 1 that Shanghai is far ahead of other NIIDZs in terms of its policy formulation level. Its policies related to technological achievement commercialization, enterprise support and talent introduction have provided precedents for other domestic counterparts. This indirectly shows the outstanding institutional innovation capability and internationalized vision of Shanghai. Chang Zhutan, though lagging behind other NIIDZs in terms of economic development level, is ahead of Beijing and Sunan in terms of transfer intensity of two policies. As the window of China's reform and opening up to the outside world, Shenzhen unexpectedly has no policies with a high transfer intensity. Thus, it can be judged that popularity of a policy is not closely related to the economic development level and opening-up degree of a NIIDZ, and that policy transfer intensity is influenced by many different factors.

\subsection{Analysis of Policy Transfer Breadth}

Under most conditions, policy transfer breadth and policy transfer intensity are positively correlated. The higher the policy transfer intensity is, the more the organizations that a policy is transferred to. However, concerning policy transfer paths in the above, this is not an absolute rule. Because of multi-transfer and self-transfer, a policy might have a high transfer intensity, but it is transferred just among few organizations. In this way, its transfer breadth will be comparatively low. Of course, there are just six NIIDZs in this paper, and this has seriously influenced policy transfer breadth. However, the six NIIDZs chosen in this paper are all representative. The policy transfer breadth reflected by them can generally show the overall development status of policy transfer in NIIDZs. In the following part, policies with a high transfer breadth are chosen to analyze the policy transfer trend in NIIDZs. 
Table 2. Transfer breadth $(>5)$ of policies in China's NIIDZs

\begin{tabular}{|c|c|c|c|c|}
\hline Item & Policy name & $\begin{array}{c}\text { Issuer } \\
\text { (NIIDZ) }\end{array}$ & Policy type & $\begin{array}{c}\text { Breadt } \\
\mathrm{h}\end{array}$ \\
\hline 1 & $\begin{array}{l}\text { Temporary Methods on Fund Management of } \\
\text { Replacing Subsidies with Rewards for Hubei } \\
\text { Provincial SME Growth Project }\end{array}$ & Wuhan & Enterprise & 6 \\
\hline 2 & $\begin{array}{c}\text { Several Suggestions for Accelerating Shenzhen } \\
\text { Municipal High-end Service Industry }\end{array}$ & Shenzhen & Industry & 5 \\
\hline 3 & $\begin{array}{l}\text { Temporary Methods on Fund Project of Hubei } \\
\text { Provincial Agricultural Technological } \\
\text { Achievement Commercialization } 2006\end{array}$ & Wuhan & $\begin{array}{c}\text { Technological } \\
\text { achievement } \\
\text { commercializatio } \\
\mathrm{n}\end{array}$ & 5 \\
\hline 4 & $\begin{array}{c}\text { Several Suggestions for Promoting Development } \\
\text { of New and High-tech Enterprises in } \\
\text { Zhongguancun }\end{array}$ & Beijing & Enterprise & 5 \\
\hline 5 & $\begin{array}{c}\text { Implementation Methods on Promoting } \\
\text { Construction of the Incubation System of } \\
\text { Technological Enterprises in Changsha } \\
\text { National High-Tech Industrial Development } \\
\text { Zone (Temporary) }\end{array}$ & $\begin{array}{l}\text { Chang } \\
\text { Zhutan }\end{array}$ & Enterprise & 5 \\
\hline 6 & $\begin{array}{l}\text { Identification and Management Methods on } \\
\text { New and High-tech Enterprises }\end{array}$ & Sunan & Enterprise & 5 \\
\hline 7 & $\begin{array}{l}\text { Temporary Management Methods on Financing } \\
\text { Subsidy Risk Compensation Funds in Donghu } \\
\text { Innovation Demonstration Zone }\end{array}$ & Wuhan & Finance & 5 \\
\hline 8 & $\begin{array}{c}\text { Several Policies for Promoting Development of } \\
\text { Shanghai Biomedical Industry }\end{array}$ & Shanghai & Enterprise & 5 \\
\hline 9 & $\begin{array}{c}\text { Measures on Implementing Shanghai Municipal } \\
\text { Small Technological Giant Project }\end{array}$ & Shanghai & Enterprise & 5 \\
\hline
\end{tabular}

Policy transfer breadth emphasizes on geographic coverage of policies. The higher the transfer breadth is, the larger the geographical coverage is. As one observes in Table 2, Temporary Methods on Fund Management of Replacing Subsidies with Rewards for Hubei Provincial SME Growth Project has been the only policy which is introduced by all the six NIIDZs in recent years. On the one hand, this suggests that all NIIDZs have paid great attention to policies promoting development of SMEs. On the other hand, it means the policy has been quite successful and a pioneer among NIIDZs. In terms of policy transfer intensity, there are no great differences among technological achievement commercialization, enterprise support and talent introduction transfer frequency. Differently, in terms of policy transfer breadth, only enterprise policies are popular among different NIIDZs. Moreover, among policies with a high transfer breadth, enterprise policies account for nearly half of the transfer breadth. This indicates that NIIDZs have paid great attention to enterprise policies. By introducing these policies, NIIDZs attempt to propel their development, which will in turn drive development of NIIDZs. Comparatively, policies issued by Wuhan receives more attention from other NIIDZs, because of a high consistency between these policies and their development. Meanwhile, there are few policies with both a high policy transfer intensity and a high policy transfer breadth. On the one hand, the phenomenon suggests frequent policy re-innovation among NIIDZs. On the other hand, it reflects differentiated policy development in NIIDZs. Each NIIDZ has their own focus. This creates the conditions for them to learn from each other.

\subsection{Analysis of Policy Transfer Speed}

Under China's current political system, once an excellent policy appears in one organization, it will gain attention from other organizations of the same kind, and be quickly referred and transferred. Meanwhile, when two NIIDZs issue a similar policy within a short period of time, it indirectly reflects similarity of development demands among policy implementers. Therefore, in terms of policy transfer speed, the faster the policy transfer 
speed is, the higher the quality of a policy transferred is, and the more consistent the policy is with development needs of a NIIDZ.

Table 3. Top 10 policies with the highest transfer speed in China's NIIDZs (Unit: day)

\begin{tabular}{|c|c|c|c|c|}
\hline Item & Policy name & Issuer & Policy type & Speed \\
\hline 1 & $\begin{array}{c}\text { Implementation Suggestions for Promoting Listing of } \\
\text { Enterprises (Wuxi) }\end{array}$ & Sunan & Finance & 12 \\
\hline 2 & $\begin{array}{c}\text { Fund Management Methods on Supporting } \\
\text { Development of University Science Park and } \\
\text { Technological Enterprise Incubator of Zhongguancun } \\
\text { Science Park }\end{array}$ & Beijing & Enterprise & 15 \\
\hline 3 & $\begin{array}{l}\text { Several Implementation Suggestions for Developing } \\
\text { and Introducing Highly-Skilled Talents (Sunan) }\end{array}$ & Sunan & Talents & 19 \\
\hline 4 & $\begin{array}{l}\text { Notice on Printing and Issuing Methods on } \\
\text { Developing and Funding Top Talents }\end{array}$ & $\begin{array}{l}\text { Chang } \\
\text { Zhutan }\end{array}$ & Talents & 24 \\
\hline 5 & $\begin{array}{l}\text { Methods on Managing Entrepreneurship Incubation } \\
\text { Cluster of Technological Enterprises in } \\
\text { Zhongguancun Science Park (Trial Implementation) }\end{array}$ & Beijing & Enterprise & 24 \\
\hline 6 & $\begin{array}{c}\text { Several Suggestions of Beijing Municipal Government } \\
\text { on Encouraging Industry-University-Research } \\
\text { Cooperation }\end{array}$ & Beijing & $\begin{array}{l}\text { Industry-Uni } \\
\text { versity-Rese } \\
\text { arch }\end{array}$ & 37 \\
\hline 7 & $\begin{array}{l}\text { Opinions of Suzhou Industrial Park Administration } \\
\text { Committee on promoting Development of Enterprises } \\
\text { with Self-Owned Brands (Trial Implementation) }\end{array}$ & Sunan & Enterprise & 42 \\
\hline 8 & $\begin{array}{c}\text { Temporary Regulations on Strengthening Fund } \\
\text { Monitoring of Science Research Project (Research } \\
\text { Topics) }\end{array}$ & Shenzhen & $\begin{array}{l}\text { Industry-Uni } \\
\text { versity-Rese } \\
\quad \text { arch }\end{array}$ & 42 \\
\hline 9 & $\begin{array}{c}\text { Several Technological Innovation Policy Suggestions } \\
\text { of Changzhou New-and High-Tech Zone Management } \\
\text { Committee on Accelerating Construction of Sunan } \\
\text { Innovation Demonstration Zone }\end{array}$ & Sunan & Institution & 48 \\
\hline 10 & $\begin{array}{c}\text { Methods of Wuxi New-and High-Tech Zone on } \\
\text { Identifying "530” Top Talents Entrepreneurship } \\
\text { Projects }\end{array}$ & Wuhan & Talents & 49 \\
\hline
\end{tabular}

As shown in Table 3, the transfer speed of policies related to enterprise development and talent introduction is fast, which is also in line with the basic development rules. Though different NIIDZs have sought differentiated development by adjusting measures to local conditions, they are all faced with shortage of technological enterprises and talents, because they are organizations of the same kind and competitors to each other. One way for NIIDZs to avoid lagging behind is to refer to each other's development to seek the optimal policies and seize more development resources. From Table 3, it can be seen that policies issued by Sunan and Beijing are quickly transferred out. As to the reason behind the phenomenon, the author thinks that Sunan has a vast development area. Many branches in it develop in different directions. This enables Sunan to excel its counterparts in China in terms of the issuance number and speed of policies. Besides, diversified policies of Sunan also provide more references for other NIIDZs. These NIIDZs can adjust policies transferred from Sunan to serve their own development. As to Beijing, it acts as a pioneer of NIIDZs. Many national policies are first tried in Beijing. Because of that, many other NIIDZs regard Beijing as a benchmark, and respond quickly to policy changes of Beijing.

\subsection{Quantitative Analysis of Policy Transfer}

Policy transfer is a movement process of policies in terms of time and space. Quantization of policy transfer 
cannot be judged simply in terms of how many times a policy is transferred. Other factors which can also influence policy transfer should also be comprehensively considered. In this paper, policy transfer quantization methods are adopted to calculate policy transfer intensity, breadth and speed. The calculation results can provide a more direct understanding of quantization of policy transfer in NIIDZs, guide policy innovation of NIIDZs, and promote their development and progress.

Table 4. Quantization results of policy (Top 10) transfer among China's NIIDZs

\begin{tabular}{|c|c|c|c|c|}
\hline Item & Policy name & Issuer & Policy type & $\begin{array}{l}\text { Quantization } \\
\text { results }\end{array}$ \\
\hline 1 & $\begin{array}{c}\text { Temporary Methods on Fund } \\
\text { Management of Replacing Subsidies with } \\
\text { Rewards for Hubei Provincial SME } \\
\text { Growth Project }\end{array}$ & Wuhan & Enterprise & 0.9002 \\
\hline 2 & $\begin{array}{c}\text { Methods on Fund Support for New and } \\
\text { High-tech Achievement } \\
\text { Commercialization }\end{array}$ & Shanghai & $\begin{array}{l}\text { Technological } \\
\text { achievement } \\
\text { commercialization }\end{array}$ & 0.8918 \\
\hline 3 & $\begin{array}{c}\text { Temporary Methods on Fund Project of } \\
\text { Hubei Provincial Agricultural } \\
\text { Technological Achievement } \\
\text { Commercialization } 2006\end{array}$ & Wuhan & $\begin{array}{c}\text { Technological } \\
\text { achievement } \\
\text { commercialization }\end{array}$ & 0.8650 \\
\hline 4 & $\begin{array}{l}\text { Several Suggestions of CPC Beijing } \\
\text { Municipal Committee and Beijing } \\
\text { Municipal People's Government on } \\
\text { Building Zhongguancun Science Park }\end{array}$ & Beijing & Institution & 0.8602 \\
\hline 5 & $\begin{array}{c}\text { Several Suggestions for Promoting } \\
\text { Development of New and High-tech } \\
\text { Enterprises in Zhongguancun }\end{array}$ & Beijing & Enterprise & 0.8082 \\
\hline 6 & $\begin{array}{l}\text { Several Suggestions on Accelerating } \\
\text { Construction and Development of } \\
\text { Technological Enterprise Incubators }\end{array}$ & Sunan & Enterprise & 0.79947 \\
\hline 7 & $\begin{array}{c}\text { Methods on Managing and Identifying } \\
\text { New and High-tech Enterprises }\end{array}$ & Sunan & Enterprise & 0.7947 \\
\hline 8 & $\begin{array}{c}\text { Measures on Implementing Shanghai } \\
\text { Municipal Small Technological Giant } \\
\text { Project. }\end{array}$ & Shanghai & Enterprise & 0.7710 \\
\hline 9 & $\begin{array}{c}\text { Several Suggestions for Accelerating } \\
\text { Shenzhen Municipal High-end Service } \\
\text { Industry }\end{array}$ & Shenzhen & Enterprise & 0.7565 \\
\hline 10 & $\begin{array}{l}\text { Suggestions of Suzhou Industrial Park } \\
\text { for Encouraging Entrepreneurship } \\
\text { among Top Technological Talents }\end{array}$ & Sunan & Talents & 0.7558 \\
\hline
\end{tabular}

Quantization results of policy transfer intensity, breadth and speed can provide a quantitative perspective for policy transfer research. From the quantization results, it can be seen that, the higher the value is, the more leading a policy is in terms of transfer intensity, breadth and speed. In Table 4, the quantitative value of enterprise policies is relatively high. This suggests that enterprise policies are the most likely to be transferred out. Take a close look at Table 4, and one can observe that, among five enterprise policies with a high quantitative value, four are targeted at developing enterprises, and the remaining one is about methods to identity new-and high-tech enterprises, which are also regulations seeking rapid development of enterprises. Besides, enterprise policies cover every development period of local technological enterprises, including development institutions for enterprises, incubation of technology-oriented enterprises, development of SMEs and 
internationalization of technological enterprises. It is apt to say that enterprise policies have become the policy development focus of different NIIDZs, and that innovational enterprise policies are more frequently transferred among NIIDZs. Undoubtedly, growth of technological enterprises cannot be separated from support of scientific research and scientific research industrialization. As the development foundation of NIIDZs, technological achievement commercialization relies on policy guidance and fund leverage of NIIDZs to maximally promote technological content of products. Therefore, technological achievement commercialization policies are the second most-transferred policies among NIIDZs, following enterprise policies.

Cooperation and competition coexist among NIIDZs. As to competition, NIIDZs have similar resource demands, such as talents, and they need to compete for more of such resources so as to get ahead. On the other hand, they compete with each other in terms of development concepts and economic output. In fact, both competition and cooperation can promote policy transfer among NIIDZs. All NIIDZs want to be a pioneer in issuing certain policy, because it means more social resources and more development opportunities can be seized. Meanwhile, when a well-functioning policy is issued by one NIIDZ, other NIIDZs will quickly catch up. Therefore, NIIDZs with a high quantitative value of policy transfer are usually in a leading position in terms of policies issued by them. In table 4, apart from Chang Zhutan, all the other NIIDZs have frequently-transferred policies, and their policy development level is quite balanced. Among them, Sunan is slightly ahead in terms of the number of policy innovations, but its policy transfer quantization result lags behind. Survey shows that Sunan and Chang Zhutan are relatively new. Particularly, Chang Zhutan is in Central China. It is far behind other NIIDZs in terms of economy, technology and many other aspects. Thus, the poor policy transfer quantization result of Chang Zhutan is within expectation. As to Sunan, which though newly-established enjoys a developed economy and has many branches within it, the number of policies issued by it is the highest among all, but the quality of its policies is behind that of others.

\section{Conclusions}

Based on the policy transfer link of China's NIIDZs, this paper proposes three indexes, including policy transfer intensity, breadth and speed, to describe policy transfer. Next, a policy transfer quantitative evaluation methodological system is built, after quantization of policy transfer frequency, policy coverage and policy adoption time. Following that, connotation of policy transfer among NIIDZs is analyzed in view of quantitative policy transfer results. Then, by classifying policies transferred into different types, the author explores the relationship between policy transfer quantization results and policy types at an attempt to provide references for policy innovation and development of NIIDZs.

Through the above analysis and discussion, this paper comes up with three research findings. First, enterprise policies, exceling in terms of policy transfer intensity, breadth and speed, have become policy development focus of all NIIDZs, and are more easily transferred out. Second, talent policies are fast in transfer speed. Development of NIIDZs cannot be separated from talent support. In order to attract top talents, NIIDZs have spared no efforts in terms of talent introduction, and are also sensitive to talent policies issued by their counterparts. Third, apart from Chang Zhutan with a low economic development level, all the other NIIDZs studied in this paper are similar in terms of their policy innovation and transfer level. Comparatively, policy transfer of Wuhan and Shanghai is mainly reflected as transfer of enterprise support and technological achievement commercialization; Beijing has achieved remarkable achievements in terms of institutional construction and enterprise policies; Shenzhen emphasizes more on industrial policies; and Sunan is leading in terms of enterprise and talent policies relying on its hinterland advantages and favorable economic development.

To sum up, this paper conducts a textual analysis of policies of China's NIIDZs, refines their policy transfer links and proposes a complete policy transfer quantitative index system. It also analyzes the development trend of policy transfer among these NIIDZs from a quantitative perspective in the hope of providing data support for their policy development and in-depth policy integration. Of course, this research also has its limits. For example, there are just six research samples selected in this paper. Since quantitative research of policy transfer is still a brand-new research direction of policy transfer studies, the author will proceed from policy texts to analyze the relationship between policy transfer quantization results and textual content; explore the relationship between policy transfer and policy coordination, as well as the factors that affect the transfer of policy, to further explore the quantitative aspects of policy transfer.

\section{References}

Audretsch, D. B., Lehmann, E. E., \& Paleari, S. (2015). Academic policy and entrepreneurship: A European

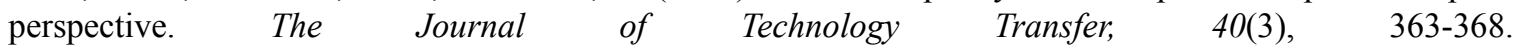
https://doi.org/10.1007/s10961-014-9359-6 
Bai, L., Qiao, Q., Yao, Y., Guo, J., \& Xie, M. (2014). Insights on the development progress of National Demonstration eco-industrial parks in China. Journal of Cleaner Production, 70, 4-14. https://doi.org/10.1016/j.jclepro.2014.01.084

Bichler, J., \& Schmidkonz, C. (2014). The Chinese indigenous innovation system and its impact on foreign enterprises. Munich Business School Working Paper, University of Applied Sciences.

Chen, D., Chen, D., Wei, W., Wei, W., Hu, D., Hu, D., ... Muralidharan, E. (2016). Survival strategy of OEM companies: a case study of the Chinese toy industry. International Journal of Operations \& Production Management, 36(9), 1065-1088. https://doi.org/10.1108/ijopm-04-2015-0212

Cook, I. R. (2008). Mobilising urban policies: The policy transfer of US Business Improvement Districts to England and Wales. Urban Studies, 45(4), 773-795. https://doi.org/10.1177/0042098007088468

d'Aquino, P., \& Bah, A. (2014). Multi-level participatory design of land use policies in African drylands: A method to embed adaptability skills of drylands societies in a policy framework. Journal of environmental management, 132, 207-219. https://doi.org/10.1016/j.jenvman.2013.11.011

Dolowitz, D. P., \& Marsh, D. (2000). Learning from abroad: The role of policy transfer in contemporary policy-making. Governance, 13(1), 5-23. https://doi.org/10.1111/0952-1895.00121

Dolowitz, D., \& Marsh, D. (1996). Who learns what from whom: a review of the policy transfer literature. Political studies, 44(2), 343-357. https://doi.org/10.1111/j.1467-9248.1996.tb00334.x

Dong, J., Chi, Y., Zou, D., Fu, C., Huang, Q., \& Ni, M. (2014). Energy-environment-economy assessment of waste management systems from a life cycle perspective: Model development and case study. Applied Energy, 114, 400-408. https://doi.org/10.1016/j.apenergy.2013.09.037

Dunlop, C. A. (2009). Policy transfer as learning: capturing variation in what decision-makers learn from epistemic communities. Policy studies, 30(3), 289-311. https://doi.org/10.1080/01442870902863869

Evans, M., \& Davies, J. (1999). Understanding policy transfer: A Multi-level, multi-disciplinary perspective. Public administration, 77(2), 361-385. https://doi.org/10.1111/1467-9299.00158

Gao, X., Song, W., \& Peng, X. (2015). National Innovation Demonstration Zones Leading China's Regional Development. Modern Economy, 6(10), 1056. https://doi.org/10.4236/me.2015.610102

Gorton, M., Hubbard, C., \& Hubbard, L. (2009). The folly of European Union policy transfer: why the Common Agricultural Policy (CAP) does not fit Central and Eastern Europe. Regional Studies, 43(10), 1305-1317. https://doi.org/10.1080/00343400802508802

Gray, V. (1973). Innovation in the states: A diffusion study. American political science review, 67(04), 1174-1185. https://doi.org/10.2307/1956539

Heilmann, S., Shih, L., \& Hofem, A. (2013). National planning and local technology zones: Experimental governance in China's Torch Programme. The China Quarterly, 216, 896-919. https://doi.org/10.1017/s0305741013001057

Huang, Y., Audretsch, D. B., \& Hewitt, M. (2013). Chinese technology transfer policy: The case of the national independent innovation demonstration zone of East Lake. The Journal of Technology Transfer, 38(6), 828-835. https://doi.org/10.1007/s10961-012-9292-5

Ishengoma, E., \& Vaaland, T. I. (2016). Can university-industry linkages stimulate student employability?. Education+ Training, 58(1), 18-44. https://doi.org/10.1108/et-11-2014-0137

Knill, C. (2005). Introduction: Cross-national policy convergence: concepts, approaches and explanatory factors. Journal of European public policy, 12(5), 764-774. https://doi.org/10.1080/13501760500161332

Li, Y., Zhan, C., de Jong, M., \& Lukszo, Z. (2016). Business innovation and government regulation for the promotion of electric vehicle use: lessons from Shenzhen, China. Journal of Cleaner Production, 134, 371-383. https://doi.org/10.1016/j.jclepro.2015.10.013

Lin, Z. J., Liu, M., \& Zhang, X. (2016). The Development of Corporate Governance in China. Asia-Pacific Management Accounting Journal, 1(1).

McCann, E., \& Ward, K. (2013). A multi-disciplinary approach to policy transfer research: geographies, assemblages, mobilities and mutations. Policy Studies, 34(1), 2-18. https://doi.org/10.1080/01442872.2012.748563

Mossberger, K., \& Wolman, H. (2003). Policy transfer as a form of prospective policy evaluation: Challenges 
and recommendations. Public Administration Review, 63(4), 428-440. https://doi.org/10.1111/1540-6210.00306

Prince, R. (2010). Policy transfer as policy assemblage: making policy for the creative industries in New Zealand. Environment and Planning A, 42(1), 169-186. https://doi.org/10.1068/a4224

Strbac, G., Pollitt, M., Konstantinidis, C. V., Konstantelos, I., Moreno, R., Newbery, D., \& Green, R. (2014). Electricity transmission arrangements in Great Britain: Time for change?. Energy Policy, 73, 298-311. https://doi.org/10.1016/j.enpol.2014.06.014

Walker, J. L. (1969). The diffusion of innovations among the American states. American political science review, 63(03), 880-899. https://doi.org/10.2307/1954434

Wolman, H., \& Page, E. (2002). Policy transfer among local governments: An information-theory approach. Governance, 15(4), 577-501. https://doi.org/10.1111/1468-0491.00198

Zhang, J., Huang, C., Ye, X.-T., Shi, K., \& Su, J. (2016). Study on China's Public Policy Diffusion Based on the Quantitative Analysis of Policy Documents: A Case Study on Policies Promoting Commercialization of Scientific and Technological Achievements. China Soft Science, (02), 145-155.

\section{Copyrights}

Copyright for this article is retained by the author(s), with first publication rights granted to the journal.

This is an open-access article distributed under the terms and conditions of the Creative Commons Attribution license (http://creativecommons.org/licenses/by/4.0/). 